\title{
TWO NEW SPECIES OF GALUMNIDAE (ACARI, ORIBATIDA) FROM MOZAMBIQUE
}

\author{
Sergey G. Ermilov ${ }^{1}$ and Marek BąKowski ${ }^{2}$ \\ ${ }^{1}$ Tyumen State University, Institute of Environmental and Agricultural Biology (X-BIO) \\ Lenina str. 25, 625000 Tyumen, Russia; corresponding author \\ E-mail:ermilovacari@yandex.ru; https://orcid.org/0000-0002-0913-131X \\ ${ }^{2}$ Department of Systematic Zoology, Institute of Environmental Biology \\ Adam Mickiewicz University, Uniwersytetu Poznańskiego 6, 61-614 Poznań, Poland \\ E-mail: bakowski@amu.edu.pl; https://orcid.org/0000-0002-9662-7347
}

Two new species of the family Galumnidae are described from soil-litter in the riverine forest of Gorongosa National Park (Central Mozambique). Allogalumna mozambiquensis Ermilov sp. $\mathbf{n}$. differs from all species of the genus by the morphology of bothridial seta (with the head having a long setiform tip). Neoctenogalumna gorongosaensis Ermilov sp. $\mathbf{n}$. is similar to $N$. congoensis in the bothridial seta with developed head, specific notogastral ornamentation and narrowly elongate postanal porose area, but differs from the latter by the smaller body size, heavily ciliate bothridial seta and diagonal position of adanal lyrifissure.

Key words: galumnid mites, taxonomy, morphology, Afrotropical region, new species, Galumnidae.

\section{INTRODUCTION}

The Mozambican oribatid mite (Acari, Oribatida) fauna almost unknown; only a few marine associated species were registered (Marshall \& PUGH 2000, 2002). During taxonomic identification of representatives of the family Galumnidae collected from Gorongosa National Park (Central Mozambique), we found two new species belonging to the genera Allogalumna Grandjean, 1936 and Neoctenogalumna Ermilov, Starý, Sandmann, Marian et Maraun, 2013. The primary goal of our paper is to describe and illustrate these new species.

Allogalumna was proposed by GrandJEAN (1936) with Galumna alamellae Jacot, 1935 as type species. At present, the genus comprises two subgenera and more than 50 species, having a cosmopolitan distribution (Ermilov \& KLIMOV 2017). Identification keys to some species of Allogalumna are given by BALOGH and Balogh (2002), Akrami (2015), Ermilov and Starý (2020). Neoctenogalumna was proposed by ERMiLov et al. (2013) with Ctenogalumna moresonensis Engelbrecht, 1972 as type species. The genus comprises two subgenera and three species distributed in the Ethiopian and Neotropical regions (ERMILOv \& KLImov 2017). An identification key to all species of Neoctenogalumna is given by ERmilov et al. (2013). The generic and subgeneric diagnoses of Allogalumna and Neoctenogalumna were summarized by Ermilov and Klimov (2017). 


\section{MATERIAL AND METHODS}

Specimens. Substrate samples containing oribatid mites were collected by hand method in the Gorongosa National Park $\left(4000 \mathrm{~km}^{2}\right)$, which is located in the southern end of the Great African Rift Valley in central Mozambique, Southeast Africa. Mites were extracted from samples into $75 \%$ ethanol using Berlese's funnels with electric lamps (25 W) in laboratory conditions for six days.

Specimens are deposited in two institutions: the Senckenberg Museum of Natural History, Görlitz, Germany (SMNH); and the Tyumen State University Museum of Zoology, Tyumen, Russia (TSUMZ).

Observation and documentation. Specimens were mounted in lactic acid on temporary cavity slides for measurement and illustration. Body length was measured in lateral view, from the tip of the rostrum to the posterior edge of the notogaster. Notogastral width refers to the maximum width of the notogaster in dorsal view (behind pteromorph). Lengths of body setae were measured in the lateral aspect. All body measurements are presented in micrometres. Formulas for leg setation are given in parentheses according to the sequence trochanter-femur-genu-tibia-tarsus (famulus included). Formulas for leg solenidia are given in square brackets according to the sequence genu-tibia-tarsus. Drawings were made with a camera lucida using a Leica transmission light microscope "Leica DM 2500".

Terminology. Morphological terminology used in this paper follows that of Grandjean (see Ermilov \& Klimov 2017 for review and application).

Abbreviations. Prodorsum: $S=$ sublamellar line; $N=$ prodorsal leg niche; $E, T=$ lateral ridges of prodorsum; ro, le, in $b s=$ rostral, lamellar, interlamellar, and bothridial setae, respectively; $A d=$ dorsosejugal porose area; $D=$ dorsophragma; $P=$ pleurophragma. $N o-$ togaster: $s o=$ specific ornamentation; $c, l a, l m, l p, h, p=$ notogastral setae/alveoli; $A a, A 1$, $A 2, A 3=$ notogastral porose areas; $m p=$ median pore; $i a, i m, i p, i h$, ips = lyrifissures; gla = opisthonotal gland opening. Gnathosoma: $a, m, h=$ subcapitular setae; or = adoral seta; sup, inf, $d, l, c m, a c m, u l, s u, v t, l t=$ palp setae; $\omega=$ palp solenidion; $a s=$ axillary saccule; $c h a, c h b=$ cheliceral setae; $T g=$ Trägårdh's organ. Epimeral and lateral podosomal regions: $1 a, 3 b, 4 a, 4 b=$ epimeral setae; $P d I, P d I I=$ pedotecta I, II, respectively; dis = discidium; $c p c$ = circumpedal carina. Anogenital region: $g, a g$, an , ad = genital, aggenital, anal, and adanal setae, respectively; iad = adanal lyrifissure; $A p=$ postanal porose area; $p o=$ preanal organ. Legs: $\mathrm{Tr}, \mathrm{Fe}, \mathrm{Ge}, \mathrm{Ti}$, $\mathrm{T} a=$ leg trochanter, femur, genu, tibia, and tarsus, respectively; $\omega, \phi, \sigma=$ leg solenidia; $\varepsilon=$ leg famulus; $d, l, v, b v, e v, f t, t c, i t, p, u, a, s, p v, p l=$ leg setae; $p a=$ porose area.

\section{TAXONOMY \\ Family Galumnidae \\ Genus Allogalumna Grandjean, 1936}

Type species: Galumna alamellae Jacot, 1935

\section{Allogalumna (Allogalumna) mozambiquensis Ermilov sp. $\mathrm{n}$.}

(Figs 1-3)

Diagnosis. Body size: 315-332 × 249-257. Rostral seta of medium length, lamellar seta short, both setiform, roughened. Interlamellar seta minute. Bothridial seta long, with unilaterally dilated head having some cilia and well de- 
veloped apical setiform tip. Dorsosejugal and postanal porose areas elongate oval. Dorsosejugal suture interrupted medially. Four pairs of porose areas developed, $A a$ transversely elongate triangular, $A 1$ rounded, $A 2$ and $A 3$ elongate oval. Median pore present. Epimeral and anogenital setae short, setiform, roughened. Circumpedal carina absent. Solenidion on tibia IV inserted in the middle part of the segment.

Description of adult. Measurements. Body length: 315 (holotype: male), 315-332 (four paratypes, four males); notogaster width: 249 (holotype), 249-257 (four paratypes).

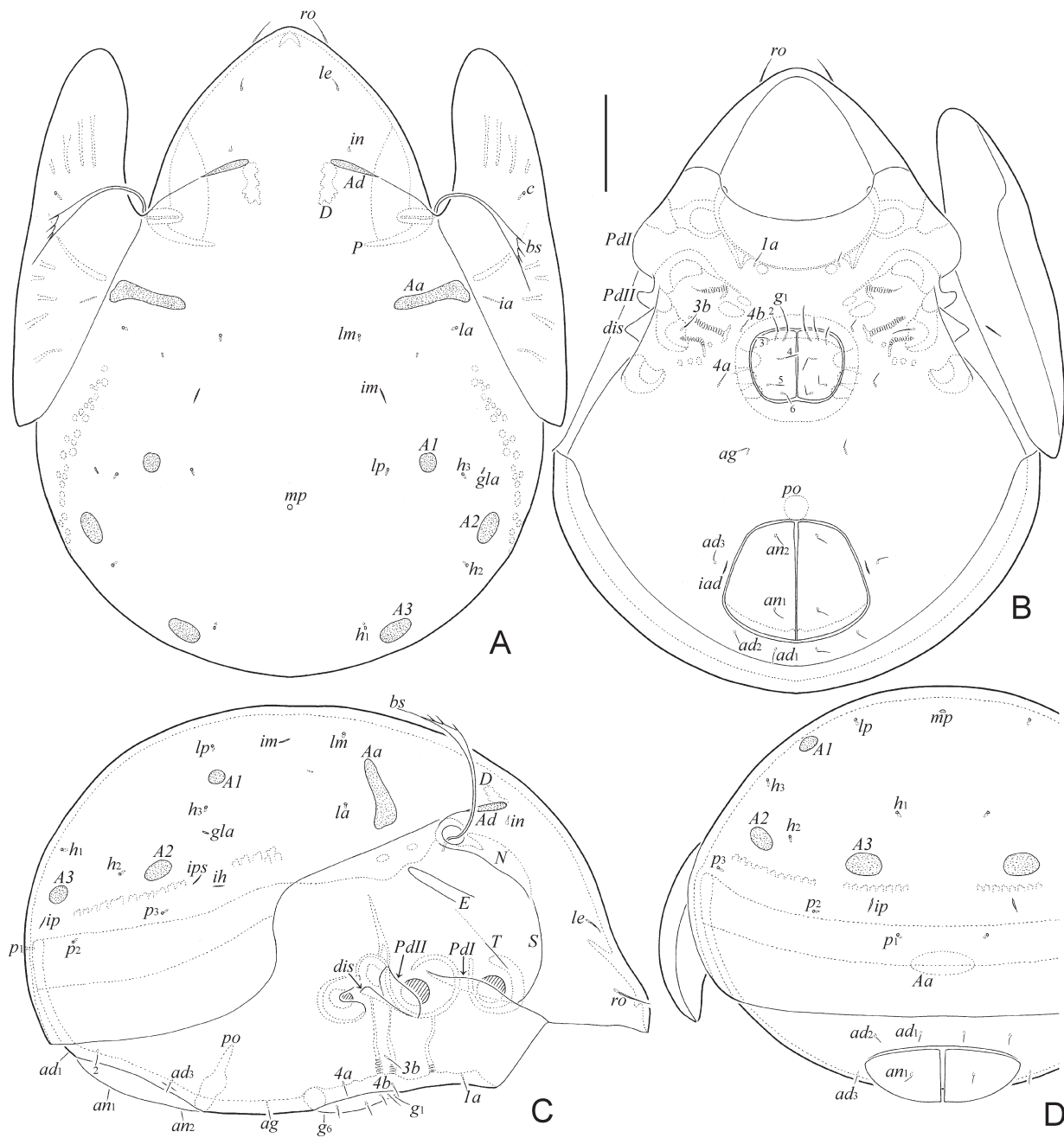

Fig. 1. Allogalumna mozambiquensis Ermilov sp. n., adult: $\mathrm{A}=$ dorsal view, $\mathrm{B}=$ ventral view (gnathosoma, legs and right pteromorph not shown), $\mathrm{C}=$ lateral view (gnathosoma, legs and pteromorph not shown), $\mathrm{D}=$ posterior view. Scale bar: $50 \mu \mathrm{m}$ 


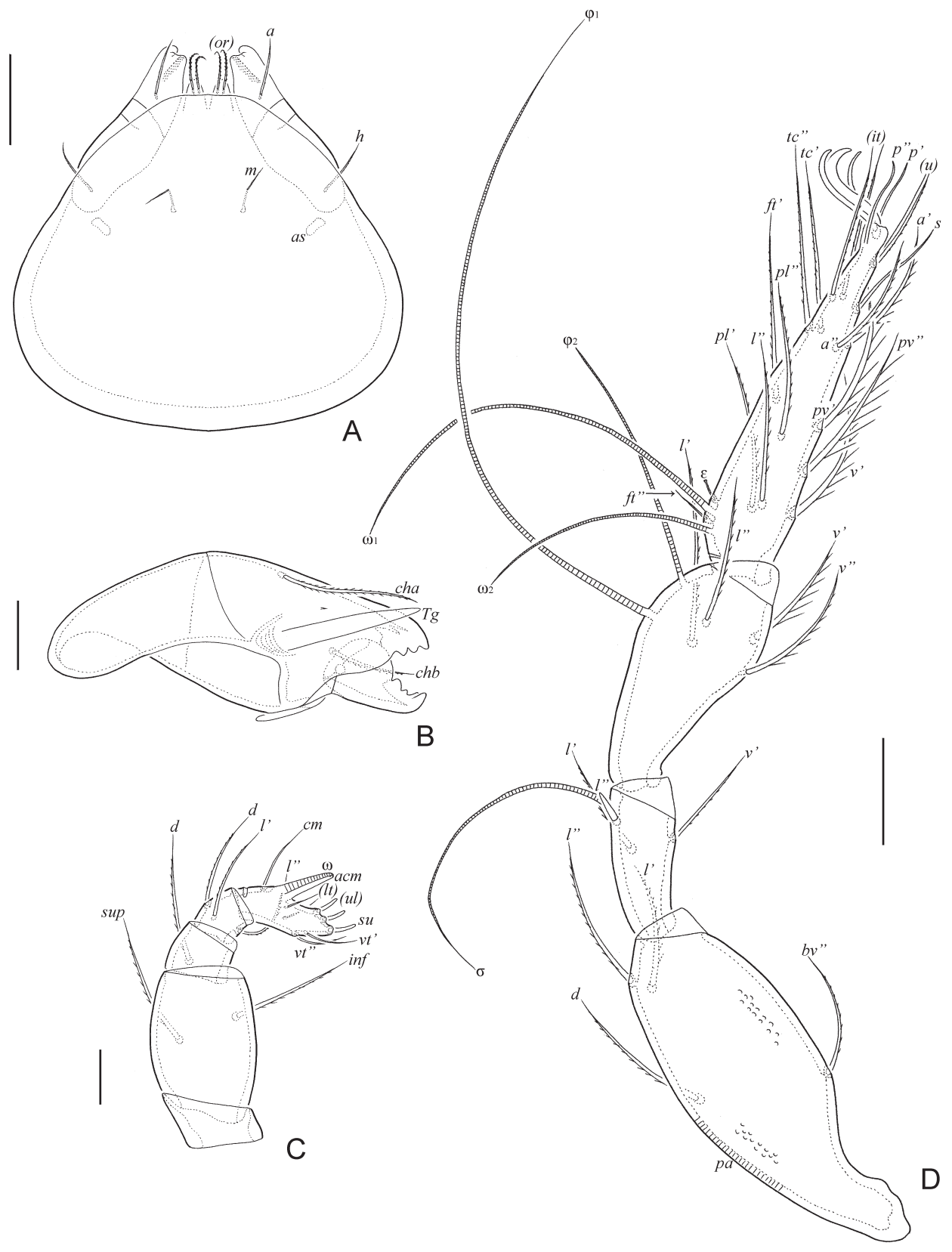

Fig. 2. Allogalumna mozambiquensis Ermilov sp. n., adult: $\mathrm{A}=$ subcapitulum, ventral view, $\mathrm{B}=$ chelicera, left, paraxial view, $\mathrm{C}=$ palp, left, paraxial view, $\mathrm{D}=$ leg I, without trochanter, right, antiaxial view. Scale bar: $20 \mu \mathrm{m}(\mathrm{A}, \mathrm{B}, \mathrm{D}), 10 \mu \mathrm{m}(\mathrm{C})$ 
Integument. Body color light brown. Body surface microporose (visible under high magnification in dissected specimens, $\times 1000$ ). Leg femora I-IV and trochanters III, IV partially tuberculate.

Prodorsum (Fig. 1A, C). Rostrum rounded. Lateral structure $N$ and ridges $E, T$ well visible. Rostral (18-20) and lamellar (6-8) setae setiform, roughened; ro thicker than le. Interlamellar seta (2) setiform, thin, smooth. Bothridial seta (73-77) with longer stalk and shorter, elongate, unilaterally dilated head having three or four cilia and well developed apical setiform tip. Dorsosejugal porose area elongate oval (22-24 × 6-8), transversely oriented, located posterior to interlamellar seta. Dorsophragma distinctly elongated longitudinally.

Notogaster (Fig. 1A, C, D). Dorsosejugal suture interrupted medially. Ten pairs of setal alveoli present. Four pairs of porose areas developed: $A 1$ transversely elongate triangular (length 10-14); $A 1$ rounded (12-16); $A 2$ and $A 3$ elongate oval (16-20 × 12). Porose area $A a$ located close to pteromorphal hinge, anterior to setal alveolus la. Median pore represented by one fovea located posterior to virtual line connected porose areas $A 1$. Opisthonotal gland opening and all lyrifissures distinct: gla located lateral to $A 1$ and removed from it; im between $l m$ and $A 1$ (equal removed from them); ip posterior to $A 3$; ih and ips close to each other, anterior to $p_{3}$ and removed from it.

Gnathosoma (Fig. 2A-C). Size of subcapitulum: 86-90 × 73-77. Subcapitular setae ( $a$ : $14-16 ; m: 12-14 ; h$ : $6-8)$ setiform, slightly barbed; $h$ thinnest. Adoral seta $(10-12)$ setiform, barbed. Length of chelicera: 102-106. Cheliceral setae (cha: 36-38; chb: 20-24) setiform, barbed. Length of palp: 65-69. Postpalpal seta (4) spiniform, smooth.

Epimeral and lateral podosomal regions (Fig. 1B, C). Epimeral setal formula: 1-0-12. Setae (3b: 8-10; 1a, 4a, 4b: 4) setiform, thin, roughened. Pedotectum II rounded in ventral aspect. Discidium triangular. Circumpedal carina completely absent.

Anogenital region (Fig. 1B-D). Genital $\left(g_{1}: 10-12 ; g_{2}: 8 ; g_{3}-g_{6}: 4\right)$, aggenital (4), anal (4), and adanal (4) setae setiform, thin, roughened. Anterior edge of genital plate with three setae. Aggenital seta located between genital and anal apertures, slightly closer to the former. Adanal lyrifissure located close and parallel to anal plate. Adanal setae $a d_{1}$ and $a d_{2}$ posterior, $a d_{3}$ lateral to anal plate and iad. Distance $a d_{1}-a d_{2}$ shorter than $a d_{2}-a d_{3}$. Unpaired postanal porose area elongate oval (24-28 $\times 12)$.

Legs (Figs 2D, 3A-C). Median claw distinctly thicker than lateral claws, all smooth. Formulas of leg setation and solenidia: I (1-4-3-4-20) [1-2-2], II (1-4-3-4-15) [1-1-2], III (1-2-1-3-15) [1-1-0], IV (1-2-2-3-12) [0-1-0]; homology of setae and solenidia indicated in Table 1. Famulus of tarsus I mini-stickform, slightly swollen and blunt-ended apically, inserted anterior to solenidion $\omega_{1}$. Seta $s$ of tarsus I eupathidial, located before setae $a$. Solenidia $\omega_{1}$ and $\omega_{2}$ on tarsus II and $\sigma$ on genu III bacilliform, other solenidia setiform. Solenidion on tibia IV inserted in the middle part of the segment.

Material examined. Holotype (male) and four paratypes (four males): Mozambique, $18^{\circ} 29^{\prime} 00.1^{\prime \prime}$; $34^{\circ} 02^{\prime} 34.6^{\prime \prime}$ E, Sofala Province, Gorongosa District, Gorongosa National Park, $842 \mathrm{~m}$ a.s.l., soil-litter in riverine forest near Murombodzi Waterfall, 14.05.2019 (collected by Marek Bąkowski).

Type deposition. The holotype is deposited in the collection of the SMNH; four paratypes are deposited in the collection of the TSUMZ. All specimens are preserved in $70 \%$ solution of ethanol with a drop of glycerol. 
Etymology. The specific name mozambiquensis refers to the country of origin, Mozambique.

Remarks. Allogalumna mozambiquensis Ermilov sp. $\mathbf{n}$. differs from all species of the subgenus (and genus) by the bothridial seta with head having long setiform tip (versus setiform tip absent).

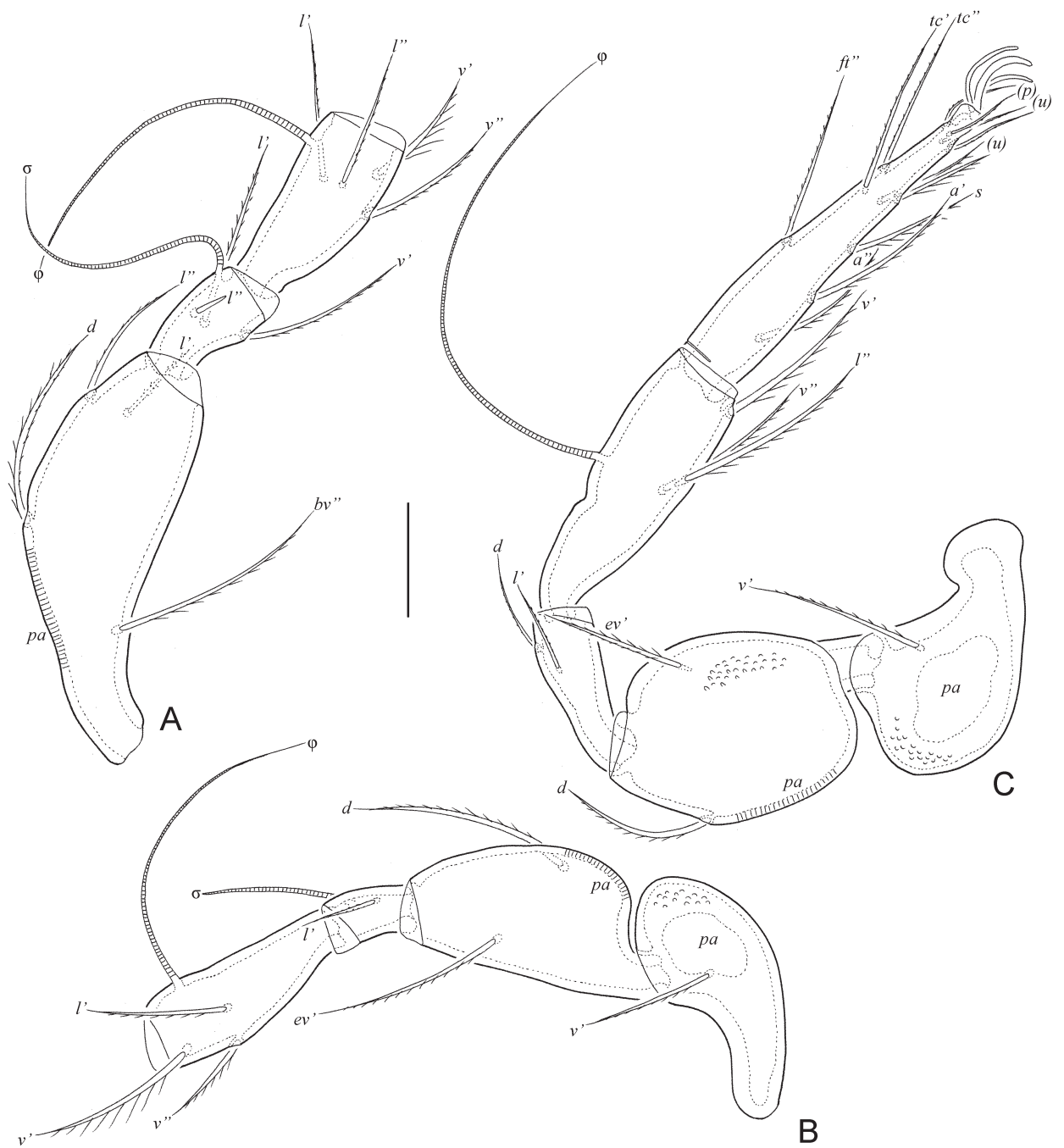

Fig. 3. Allogalumna mozambiquensis Ermilov sp. n., adult: A = leg II, without trochanter and tarsus, right, antiaxial view, B = leg III, without tarsus, right, antiaxial view, $\mathrm{C}=$ leg IV, left, antiaxial view. Scale bar: $20 \mu \mathrm{m}$ 


\section{Genus Neoctenogalumna \\ Ermilov, Starý, Sandmann, Marian et Maraun, 2013}

Type species: Ctenogalumna moresonensis Engelbrecht, 1972

\section{Neoctenogalumna (Neoctenogalumna) gorongosaensis Ermilov sp. n.} (Figs 4-6)

Diagnosis. Body size: 298-332 × 190-207. Rostral and lamellar setae of medium length, setiform, roughened. Interlamellar seta minute. Bothridial seta clavate, heavily ciliate. Dorsosejugal porose area absent. Dorsosejugal suture slightly concave medially. Notogaster with specific ornamentation. Three pairs of rounded porose areas developed, $A 2$ not observed. Median pore present. Epimeral and anogenital setae short, setiform, roughened. Circumpedal carina present. Postanal porose area narrowly elongate oval. Solenidion on tibia IV inserted in anterior part of the segment.

Description of adult. Measurements. Body length: 315 (holotype: female), 298-332 (paratypes: one male and three females); notogaster width: 199 (holotype), 190-207 (four paratypes).

Integument. Body color light brown. Body surface microgranulate (visible under high magnification in dissected specimens, $\times 1000$ ). Pteromorph partially slightly striate. Leg femora I-IV and trochanters III, IV partially tuberculate and striate.

Prodorsum (Fig. 4A, C). Rostrum rounded. Lateral structure $N$ and ridges $E$, $T$ well visible. Rostral and lamellar setae (14-16) setiform, roughened. Interlamellar seta (2) setiform, thin, smooth. Bothridial seta (45-49) with longer stalk and shorter, clavate head having numerous cilia. Dorsosejugal porose area absent. Dorsophragma distinctly elongated longitudinally.

Notogaster (Fig. 4A, C, D). Dorsosejugal suture complete, slightly concave medially. Anterior part of notogaster with slight median specific ornamentation represented by longitudinal ridge and some lateral branches. Ten pairs of short (2), setiform, thin, smooth setae present. Three pairs of rounded porose areas developed (10-12); A2 not observed. Porose area $A a$ located close to pteromorphal hinge, anterior to seta la. Median pore represented by one fovea located posterior to virtual line connected porose areas A1. Opisthonotal gland opening and all lyrifissures distinct: gla and im located close to each other, anterolateral to $A 1$ and removed from it; ip between $p_{1}$ and $p_{2}$; ih and ips close to each other, anteromedial to $p_{3}$ and removed from it.

Gnathosoma (Fig. 5A-C). Size of subcapitulum: 73-77 × 65-69. Subcapitular setae ( $a$ : $14-16 ; m: 10-12 ; h: 6)$ setiform, roughened; $h$ thinnest. Adoral seta $(10-12)$ setiform, barbed. Length of chelicera: 86-90. Cheliceral setae (cha:30-32; chb: 18-20) setiform, barbed. Length of palp: 53-57. Postpalpal seta (4) spiniform, smooth.

Epimeral and lateral podosomal regions (Fig. 4B, C). Epimeral setal formula: 1-0-12. Setae $(3 b: 8 ; 1 a, 4 a, 4 b: 4)$ setiform, thin, smooth. Pedotectum II rounded in ventral aspect. Discidium triangular. Circumpedal carina of medium length, directed to insertion of $3 b$, but distinctly no reaching of it. 
Anogenital region (Fig. 4B-D). Genital, aggenital, anal, and adanal setae (4) setiform, thin, smooth. Anterior edge of genital plate with two setae. Aggenital seta located between genital and anal apertures, equal removed from them. Adanal lyrifissure located close and diagonal to anal plate. Adanal setae $a d_{1}$ and $a d_{2}$ posterior, $a d_{3}$ lateral to anal plate and posterior to $\mathrm{iad}$. Distance $a d_{1}-a d_{2}$ slightly shorter than $a d_{2}-a d_{3}$. Unpaired postanal porose area narrowly elongate oval $(32 \times 8)$.

Legs (Figs 5D, 6A-C). Median claw distinctly thicker than lateral claws, all smooth. Formulas of leg setation and solenidia: I (1-4-3-4-20) [1-2-2], II (1-4-3-4-15) [1-1-2],

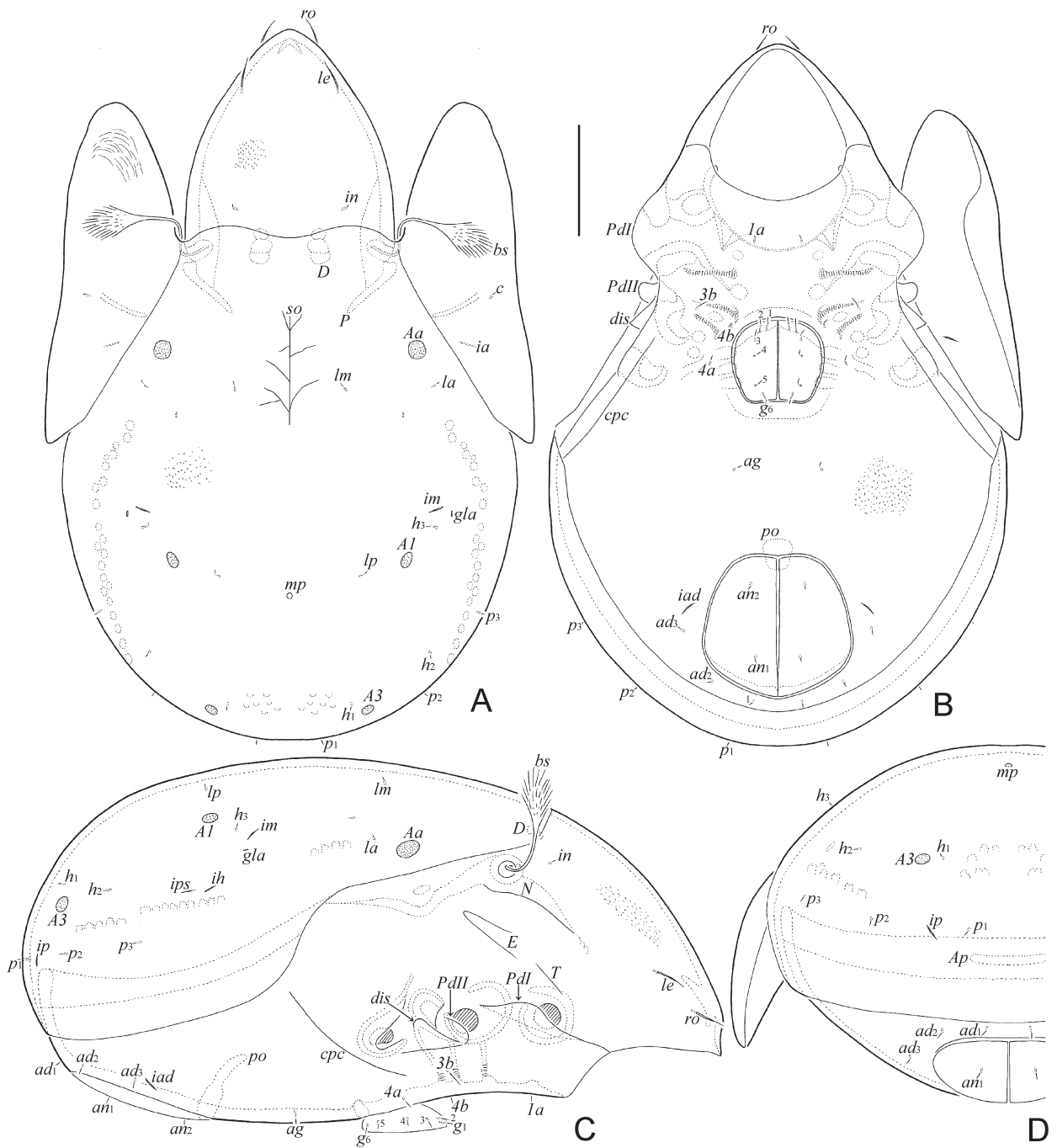

Fig. 4. Neoctenogalumna gorongosaensis Ermilov sp. $\mathbf{n}$., adult: $\mathrm{A}=$ dorsal view, $\mathrm{B}=$ ventral view (gnathosoma, legs and right pteromorph not shown), $\mathrm{C}=$ lateral view (gnathosoma, legs and pteromorph not shown), D = posterior view. Scale bar: $50 \mu \mathrm{m}$ 
III (1-2-1-3-15) [1-1-0], IV (1-2-2-3-12) [0-1-0]; homology of setae and solenidia indicated in Table 1. Famulus of tarsus I mini-stickform, slightly swollen and blunt-ended apically, inserted between solenidia $\omega_{1}$ and $\omega_{2}$. Seta $s$ of tarsus I eupathidial, located before
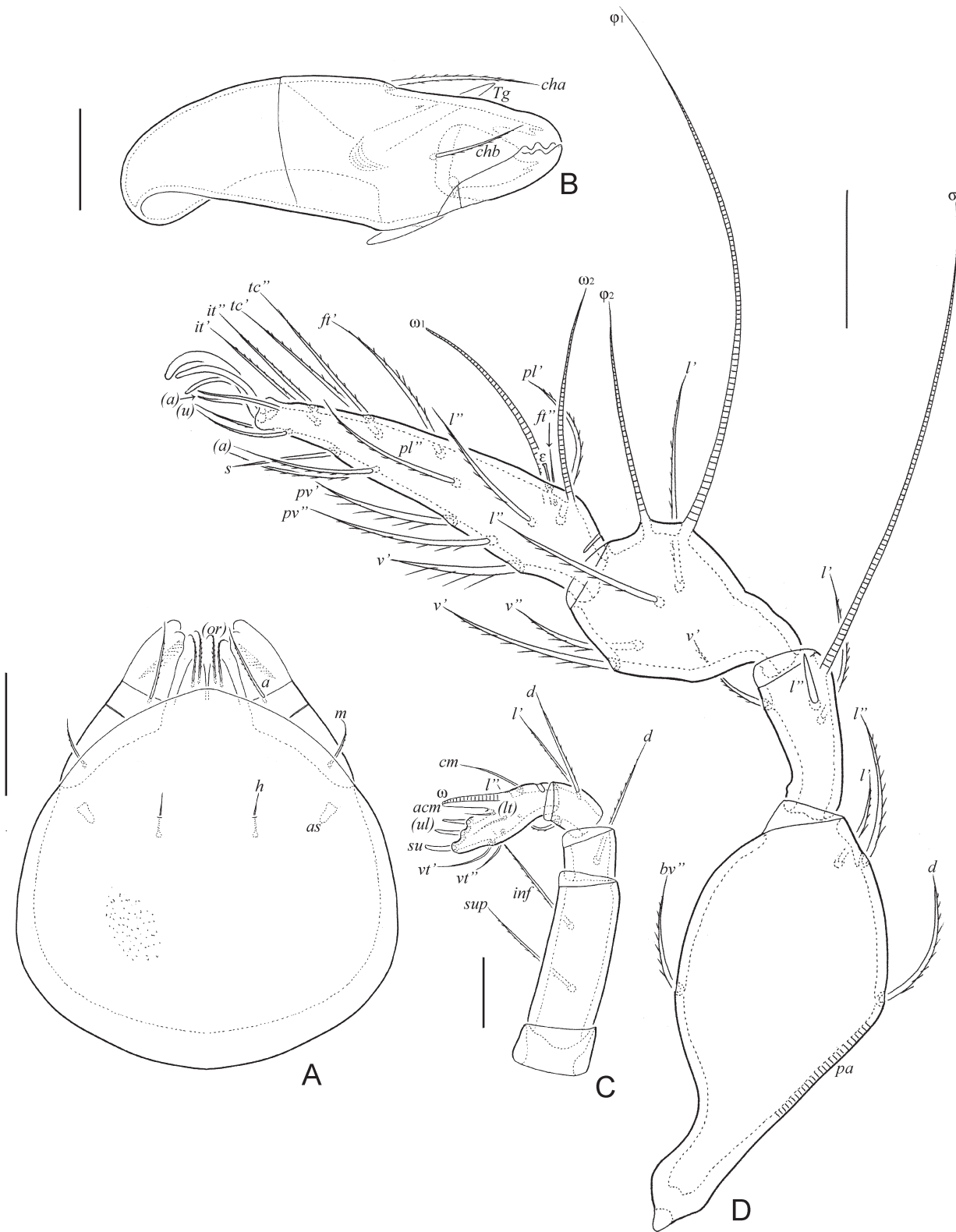

Fig. 5. Neoctenogalumna gorongosaensis Ermilov sp. $\mathbf{n}$., adult: $\mathrm{A}=$ subcapitulum, ventral view, $\mathrm{B}=$ chelicera, right, antiaxial view, $\mathrm{C}=$ palp, right, paraxial view, $\mathrm{D}-\mathrm{leg} \mathrm{I}$, without trochanter, left, antiaxial view. Scale bar: $20 \mu \mathrm{m}(\mathrm{A}, \mathrm{B}, \mathrm{D}), 10 \mu \mathrm{m}(\mathrm{C})$ 
setae $a$. Solenidia $\omega_{1}$ on tarsus I, $\omega_{1}$ and $\omega_{2}$ on tarsus II and $\sigma$ on genu III bacilliform, other solenidia setiform. Solenidion on tibia IV inserted in anterior part of the segment.

Material examined. Holotype (female) and four paratypes (one male and three females): Mozambique, $18^{\circ} 29^{\prime} 00.1^{\prime \prime} \mathrm{S} ; 4^{\circ} 02^{\prime} 34.6^{\prime \prime} \mathrm{E}$, Sofala Province, Gorongosa District, Gorongosa National Park, 842 m a.s.l., soil-litter in riverine forest near Murombodzi Waterfall, 14.05.2019 (collected by Marek Bąkowski).

Type deposition. The holotype is deposited in the collection of the SMNH; four paratypes are deposited in the collection of the TSUMZ. All specimens are preserved in $70 \%$ solution of ethanol with a drop of glycerol.

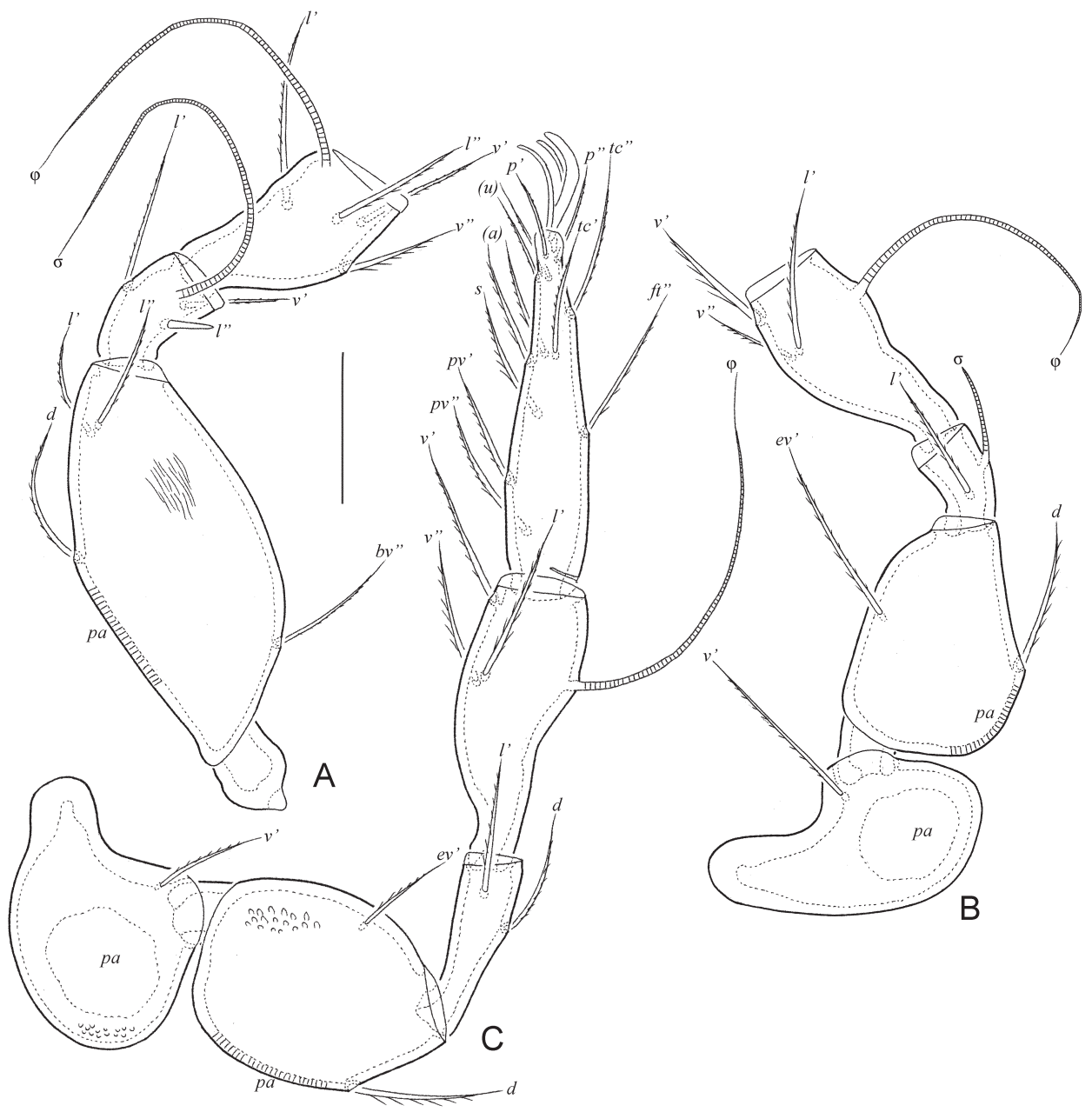

Fig. 6. Neoctenogalumna gorongosaensis Ermilov sp. n., adult: $\mathrm{A}=$ leg II, without trochanter and tarsus, right, antiaxial view, B = leg III, without tarsus, right, antiaxial view, $\mathrm{C}=$ leg IV, left, antiaxial view. Scale bar: $20 \mu \mathrm{m}$ 
Table 1. Leg setation and solenidia of adult Allogalumna mozambiquensis Ermilov sp. n. and Neoctenogalumna gorongosaensis Ermilov sp. n.

\begin{tabular}{lccccc}
\hline Leg & Tr & Fe & Ge & Ti & Ta \\
\hline I & $v^{\prime}$ & $d,(l), b v^{\prime \prime}$ & $(l), v^{\prime}, \sigma$ & $(l),(v), \phi_{1^{\prime}}, \phi_{2}$ & $(f t),(t c),(i t),(p),(u),(a), s,(p v), v^{\prime},(p l), l^{\prime \prime}$, \\
II & $v^{\prime}$ & $d,(l), b v^{\prime \prime}$ & $(l), v^{\prime}, \sigma$ & $(l),(v), \phi$ & $(f t),(t c),(i t),(p),(u),(a), s,(p v), \omega_{1}, \omega_{2}$ \\
III & $v^{\prime}$ & $d, e v^{\prime}$ & $l^{\prime}, \sigma$ & $l^{\prime},(v), \phi$ & $(f t),(t c),(i t),(p),(u),(a), s,(p v)$ \\
IV & $v^{\prime}$ & $d, e v^{\prime}$ & $d, l^{\prime}$ & $l^{\prime},(v), \phi$ & $f^{\prime \prime},(t c),(p),(u),(a), s,(p v)$ \\
\hline
\end{tabular}

Note: Roman letters refer to normal setae, Greek letters to solenidia (except $\varepsilon=$ famulus). Single prime (') marks setae on anterior and double prime (") setae on posterior side of the given leg segment. Parentheses refer to a pair of setae

Etymology. The specific name gorongosaensis refers to the place of origin, Gorongosa National Park.

Remarks. Neoctenogalumna gorongosaensis Ermilov sp. n. is morphologically most similar to N. congoensis (Starý, 2005) in the bothridial seta with developed head, specific notogastral ornamentation and narrowly elongate postanal porose area, but differs from the latter by the smaller body size (298$332 \times 190-207$ versus 388-403 × 232-245), heavily ciliate bothridial seta (versus bothridial seta barbed) and diagonal position of adanal lyrifissure (versus iad longitudinal).

Acknowledgements - The research carried out by the junior author in Gorongosa National Park was made possible through the financial support received from the Gorongosa Restoration Project and the logistical support provided by Dr. Piotr Naskręcki. Our special thanks go to Dr. Marc Stalmans for granting us research permits and for his extensive assistance provided during visits to GNP; and two anonymous reviewers for their valuable comments. Official permits to collect and transport invertebrates from Mozambique were prepared by E. O. Wilson Biodiversity Laboratory, Chitengo, GNP, 19/2019. This research was partially supported by a grant from the Russian Science Foundation, project No. 1914-00004, to P. B. Klimov.

\section{REFERENCES}

Aкrami, M. A. (2015): A new species of Allogalumna (Acari, Oribatida, Galumnidae) from Iran, including a key to all species of the genus. - Acta Zoologica Academiae Scientiarum Hungaricae 63(3): 205-224. https://doi.org/10.17109/AZH.61.3.1.2015

Balogh, J. \& BAlogh, P. (2002): Identification keys to the oribatid mites of the Extra-Holarctic regions. Vol. 1. - Well-Press Publishing Limited, Miskolc, 453 pp. 
Engelbrecht, C. M. (1972): Ctenogalumna moresonensis sp. n. and Pilogalumna bloemfonteinensis sp. n., two new South African species of the subfamily Allogalumninae Balogh, 1960 (Galumnidae: Oribatei). - Acarologia 14(3): 497-510.

Ermilov, S. G. \& Klimov, P. B. (2017): Generic revision of the large-winged mite superfamily Galumnoidea (Acari, Oribatida) of the world. - Zootaxa 4357(1): 1-72. https://doi.org/10.11646/zootaxa.4357.1.1

Ermilov, S. G. \& Starý, J. (2020): Two new species of Allogalumna (Acari, Oribatida, Galumnidae) from Madagascar. - Acta Zoologica Academiae Scientiarum Hungaricae 66(2): 99-110. https://doi.org/10.17109/AZH.66.2.99.2020

Ermilov, S. G., Starý, J., Sandmann, D., Marian, F. \& Maraun, M. (2013): New taxa and new records of oribatid mites of the family Galumnidae (Acari: Oribatida) from Ecuador. - Zootaxa 3700(2): 259-270. https://doi.org/10.11646/zootaxa.3700.2.4

Grandjean, F. (1936): Les Oribates de Jean Frédéric Hermann et de son père (Arachn. Acar.). - Annales de la Société Entomologique de France 105: 27-110.

JАсот, A. P. (1935): Galumna alatus Willmann (Acari, Oribatidae). - The Annals and Magazine of Natural History (10), 15(88): 489-492. https://doi.org/10.1080/00222933508654990

Marshall, D. J. \& Pugh, P. J. A. (2000): Two new species of Schusteria (Acari: Oribatida: Ameronothroidea) from marine shores in southern Africa. - African Zoology 35(2): 201-205. https://doi.org/10.1080/15627020.2000.11657091

Marshall, D. J. \& Pugh, P. J. A. (2002): Fortuynia (Acari: Oribatida: Ameronothroidea) from the marine littoral of southern Africa. - Journal of Natural History 36(2): 173-183. https://doi.org/10.1080/00222930010002775

Starý, J. (2005): New oribatid mites of the superfamily Galumnoidea (Acari, Oribatida) from the Republic of Congo. - Biologia 60(2): 113-119.

Received February 11, 2021, accepted May 9, 2021, published August 16, 2021 